www.jmscr.igmpublication.org

Impact Factor (SJIF): 6.379

Index Copernicus Value: 79.54

ISSN (e)-2347-176x ISSN (p) 2455-0450

crossrefDOI: https://dx.doi.org/10.18535/jmscr/v6i11.40

Journal Of Medical Science And Clinical Research

IGM Publication

An Official Publication of IGM Publication

\title{
Prevalence of Thyroid autoimmunity in pregnancy and its effect in pregnancy outcome
}

\author{
Authors \\ Sanchayan Sinha ${ }^{1}$, Arpita Mandal ${ }^{2}$, Soma Gupta ${ }^{3}$, Chandana Das ${ }^{4}$ \\ ${ }^{1 \& 2}$ Junior Resident, Department of Biochemistry, NRS Medical College, Kolkata \\ ${ }^{3}$ Professor \& Head, Department of Biochemistry, NRS Medical College, Kolkata \\ ${ }^{4}$ Professor \&Head, Department of Obstetrics \&Gynaecology, NRS Medical College, Kolkata \\ Institute: Nil Ratan Sircar Medical College. Department of Biochemistry, 138 A.J.C Bose Road \\ Kolkata- 700014, India \\ Corresponding Author \\ Soma Gupta \\ Contact Number: 9831130325, Email: docsomagupta@gmail.com \\ Address: 40A, Simla Street. Kolkata 700006, India
}

\begin{abstract}
Background: Thyroid dysfunction is common in pregnancy. It is important for growth \& development of foetus. The most important cause of thyroid dysfunction in iodine sufficient areas is autoimmune thyroiditis. Thyroid peroxidase is an important enzyme for thyroid hormone biosynthesis. Anti TPO antibody is found in autoimmune thyroiditis which causes adverse fetomaternal outcome by subtle alteration of thyroid reserve.
\end{abstract}

Aims and Objectives: The study aims to find out anti TPO antibody level in pregnancy and thereafter to determine prevalence of thyroid autoimmunity. Moreover, it aims to find difference in fetomaternal outcome according to the anti TPO antibody status.

Materials and Methods: The study included the estimation of anti TPO antibody of 142 women during delivery. On the basis of values of anti TPO antibody level prevalence of thyroid autoimmunity was calculated \& the patients were divided as Anti TPO positive $(n=26)$ \& Anti TPO negative $(n=116)$. Maternal outcome of pregnancy was measured in terms of ante partum \& postpartum haemorrhage, anaemia. Foetal outcome was measured in terms of APGAR score \& birth weight of baby. The data were tabulated \& analysed using standard statistical method.

Result: Prevalence of thyroid autoimmunity was $18.3 \%$. The incidence of adverse outcome was statistically significant in thyroid autoimmunity for maternal anaemia [p value 0.0096], Low birth weight [p value 0.026], Low APGAR score [p value < 0.0001]. TSH level of the baby measured from cord blood was more in thyroid autoimmunity.

Conclusion: Feto-maternal outcome was found to be adverse in patients with thyroid autoimmunity. Ante partum \&post-partum haemorrhage was found to be more in Anti TPO Antibody positive patients. Low birth weight \& low APGAR score were observed more in cases of babies born to mothers with thyroid autoimmunity.

Keywords: Thyroid autoimmunity, Anti TPO antibody, Antepartum haemorrhage, Postpartum haemorrhage, APGAR score, Pregnancy. 


\section{Introduction}

Thyroid gland serves the important function of secreting thyroid hormone which is helpful to maintain homeostasis \& basal metabolic rate. But in pregnancy, the normal function of thyroid often becomes abnormal. In fact, thyroid dysfunction is known to be the second most common endocrinal disorder after diabetes complicating pregnancy throughout the world. ${ }^{[1]}$ After conception, the thyroid hormones play an important role to maintain the reproductive hormonal status (especially beta HCG and oestrogen), growth and neurodevelopment of foetus. ${ }^{[2]}$

Studies have shown that despite sufficient iodine intake during pregnancy, the women are still having thyroid dysfunctions as the pregnancy advances. Autoimmune thyroid disorders have been reported as most important cause for it, which are characterised by elevated levels of different thyroid autoantibodies in the peripheral circulation. Among those antibodies, Anti thyroid peroxidise (anti TPO) antibody and antithyroglobulin (anti TG) antibodies are found to be associated with pregnancy most frequently.

Thyroid peroxidase (TPO) is an enzyme that is present in the colloid of the thyroid gland, catalyzes all the steps of thyroid hormone production inside the thyroid follicle. Anti-thyroid peroxidase antibody is found in the autoimmune thyroid diseases. This antibody hampers the TPO action and thus causing defective iodination \& thyroid hormone production.

The presence of elevated thyroid autoantibody (anti thyroid peroxidase antibody) might be a marker of underlying subtle alteration in thyroid reserve. A reduction in the functional reserve of the thyroid gland is associated with reduced capacity to adapt with the physiological changes of pregnancy, which frequently causes imbalance in thyroid hormonal homeostasis. As a result, increase in concentrations of thyroid stimulating hormone is often found in pregnant women who are having increased levels of thyroid autoantibodies in circulation. ${ }^{[3]}$
Thyroid hormones can directly stimulate the angiogenic growth factor and cytokine production as well as trophoblast proliferation survival, and invasion. The presence of elevated levels of thyroid autoantibodies reflects a generalised activation of the immune system and specifically an activity of the immune system at the fetomaternal interface. ${ }^{[3]}$

So, the presence of elevated levels of anti TPO antibody can affect normal placental growth and function affecting the outcome of pregnancy, adversely causing complications like miscarriage, preterm delivery, preeclampsia, abruptio placentae, anaemia, low birth weight babies, postpartum haemorrhage. ${ }^{[4,5]}$

Though it has been found in various studies that thyroid autoimmunity is a very serious issue regarding pregnancy related complications, its true prevalence and extent of fetomaternal complications is still debatable.

So, it is very important to find out the prevalence of thyroid autoimmunity in pregnancy in our population. It is also very important to find out the extent of adverse fetomaternal outcome in those women who are having elevated levels of anti TPO antibody. Early diagnosis and proper management of the above mentioned conditions can prevent or reduce fetomaternal demise in future. But, still no concrete data for these facts are available from in West Bengal. This study is aimed to fill some part of that gap.

\section{Aims and Objectives}

1. To measure serum Anti TPO antibody levels of the samples taken from the women of $3^{\text {rd }}$ trimester of pregnancy \& find out the prevalence of thyroid autoimmunity.

2. To measure TSH \&fT4 levels of cord blood taken from those women during delivery

3. To find out fetomaternal outcome of cases with positive thyroid autoimmunity in terms of antepartum \&postpartum haemorrhages, maternal anaemia, low birth weight babies, neonatal hypothyroidism \& low APGAR score 


\section{Materials and Methods}

The study was carried out in the Department of Biochemistry of a tertiary care Hospital after obtaining necessary permission from Institutional Ethics Committee. The study period was from March 2017 to December 2017. A total of 142 pregnant women were included in the study. All women irrespective of their parity who were admitted for delivery were included in the study. Women under antithyroid medication or having other endocrinal disorders like diabetes mellitus, or known to suffer from any autoimmune disease or malignancy, or giving any history of pregnancy induced hypertension or preeclampsia were excluded from the study.

An amount of $7.5 \mathrm{ml}$ blood was collected from the median cubital vein of all study subjects by disposable plastic syringe. The needle was detached from the Nozzle and $2 \mathrm{ml}$ blood was transferred immediately into a vial containing EDTA and shaken gently. The remaining amount of blood was transferred in a clotted vial and was allowed to clot. Then the clotted vials were centrifuged. Separated serums were labelled appropriately and were stored in ultra-freezer at $20^{\circ} \mathrm{C}$ until analysis.

Anti TPO Antibody levels were measured form maternal serum samples by sandwich ELISA method. The anti TPO antibody titre $>40 \mathrm{U} / \mathrm{L}$ were taken as positive for thyroid autoimmunity. ${ }^{[6]}$

The maternal whole blood samples in the EDTA vials were stored temporarily in the in 4 to 8 degree and after transferring in laboratory they were tested for haemoglobin by Cyanmethemoglobin method.

Immediately after delivery, $5 \mathrm{ml}$ of blood collected from umbilical cord with all aseptic precautions and transferred into a clotted vial and allowed to clot. Then the serum was separated and stored in ultra-freezer.

Thyroid hormonal status of the baby was determined by measuring cord blood TSH and fT4 levels by ELISA methods.

\section{Statistical analysis}

The results obtained were tabulated in excel sheet $\&$ analysed by standard statistical methods using SPSS 20.

\section{Results}

At first, prevalence of thyroid autoimmunity in pregnancy in the study population was calculated as $18 \%$.

The distribution of study population according to status of thyroid autoimmunity is given in Figure 1.

The thyroid status of children was measured from the cord blood of the mother. The data was distributed according to Anti TPO status of the mother and is shown in Table 2.

Student $t$ test was done to find out whether there is any significant difference among the values of TSH and FT4 of the children born to the mother with anti TPO value above and below $40 \mathrm{U} / \mathrm{L}$. It was observed that

Maternal outcomes were compared for the patients having Anti TPO antibody levels $\geq 40 \mathrm{U} / \mathrm{L}$ with Anti TPO antibody <40 U/L for ante partum haemorrhage, postpartum haemorrhage and maternal anaemia (reduced haemoglobin concentration below $10 \mathrm{mg} / \mathrm{dl})$. Fetal outcomes were compared for low birth weight (IUGR/ prematurity applying Ballard score) and APGAR score (for birth asphyxia)

The incidence of adverse maternal outcome was found to be statistically significant in thyroid autoimmunity (Anti TPO Antibody positive) for maternal anaemia $(\mathrm{Hb} \%<10 \mathrm{mg} / \mathrm{dl})$ [odds ratio 2.32, $\mathrm{p}$ value $=0.0096]$

The incidence of adverse fetal outcome was found to be statistically significant in thyroid autoimmunity for the following parameters:

1. Low birth weight $(<2.5 \mathrm{~kg})$ [odd ratio 2.37, $\mathrm{p}$ value $=0.026]$

2. Low APGAR score [odd ratio 14.25, $\mathrm{p}$ value $<0.0001]$ 




Table 1: Thyroid status of children according to the anti TPO status of the mothers

\begin{tabular}{|l|c|c|}
\hline Cord blood & $\begin{array}{l}\text { Mother's Anti } \\
\text { TPO } \geq 40 \mathrm{U} / \mathrm{L}\end{array}$ & $\begin{array}{l}\text { Mother's Anti } \\
\text { TPO <40 U/L }\end{array}$ \\
\hline $\begin{array}{l}\text { TSH (mean } \\
\pm \text { SD) }\end{array}$ & $12.95( \pm 7.93)$ & $9.96( \pm 6.83)$ \\
\hline fT4 (mean \pm SD) & $1.16( \pm 0.38)$ & $1.18( \pm 0.41)$ \\
\hline
\end{tabular}

Fig. 1: Distribution of study population according

to status of thyroid autoimmunity

Table 2: Fetomaternal outcome of thyroid autoimmunity

\begin{tabular}{|l|c|c|c|c|}
\hline Fetomaternal outcome & $\begin{array}{c}\text { Anti TPO } \\
\geq 40 \mathrm{U} / \mathrm{L}(\mathrm{n}=26)\end{array}$ & $\begin{array}{c}\text { AntiTPO } \\
<40 \mathrm{U} / \mathrm{L}(\mathrm{n}=116)\end{array}$ & $\begin{array}{c}\text { Odds } \\
\text { ratio }\end{array}$ & P value \\
\hline Ante partum hemorrhage & $11.9 \%$ & $6 \%$ & 2.09 & 0.245 \\
\hline Postpartum hemorrhage & $4.7 \%$ & $3 \%$ & 1.6 & 0.634 \\
\hline Anemia $(\mathrm{Hb}<10 \mathrm{mg} / \mathrm{dl})$ & $67.5 \%$ & $29 \%$ & 2.32 & $\underline{\mathbf{0 . 0 0 9 6}}$ \\
\hline $\begin{array}{l}\text { Low birth weight babies } \\
(<2.5 \mathrm{~kg})\end{array}$ & $38 \%$ & $24 \%$ & 2.37 & $\underline{\mathbf{0 . 0 5}}$ \\
\hline $\begin{array}{l}\text { Low APGAR score }(<6 \\
\text { at 5 minute of birth) }\end{array}$ & $42 \%$ & $5 \%$ & 14.25 & $\leq \mathbf{0 . 0 5}$ \\
\hline
\end{tabular}

\section{Discussion}

India is presently having high prevalence of thyroid dysfunction among the pregnant women through last few decades. Though several etiological background of this non-communicable disease has been well explained, a number of recent literature suggest that autoimmune thyroid disease is a very important factor for hypothyroidism complicating the pregnancy resulting adverse fetomaternal outcome.

The presence of thyroid autoantibodies might be a marker of underlying subtle alteration in thyroid reserve. A reduction in the functional reserve of the thyroid gland associated with reduced adaptation to the physiological changes of pregnancy could contribute to minor changes in circulating thyroid hormone concentrations. The increase in thyroid stimulating hormone concentrations in pregnant women with thyroid autoantibodies supports this hypothesis. There is evidence that there is an alteration in cytokine expression by peripheral $\mathrm{T}$ lymphocytes in women positive for thyroid antibodies in non-pregnant women. Pregnancy is an inflammatory process involving a shift in the regulation of cytokine networks within the local placental-decidual environment. Dysregulation of local inflammatory processes can be associated with miscarriage and premature delivery. Thyroid hormones can directly influence angiogenic growth factor and cytokine production as well as trophoblast proliferation, survival, and invasion. The importance of identifying subclinical hypothyroidism and thyroid autoimmunity in early pregnancy is thus obvious as it is likely to have a profound influence on the outcome of pregnancy. The presence of thyroid autoantibodies reflects a generalised activation of the immune system and specifically an activity of the immune system at the feto-maternal interface. Autoimmune thyroid dysfunction is seen in hypothyroid, euthyroid and even in hyperthyroid state. Graves' disease accounts for $85 \%$ of all cases of hyperthyroidism, whereas Hashimoto's thyroiditis is the common cause of hypothyroidism. There is evidence of thyroid autoimmunity in causing adverse effects like miscarriage, preterm delivery, preeclampsia, abruptio placentae, anaemia, low birth weight babies, postpartum haemorrhage.

In 1990 Stagnaro- Green et al showed that among 552 women who were screened for thyroid antibodies, abortion rate of $17 \%$ was observed in 
antibody positive group as compared to $8.4 \%$ in antibody negative group ${ }^{[7]}$.

Bussen Steck et al in 1995 screened 22 nonpregnant women with bad obstetric history for thyroid antibodies and detected a higher prevalence of thyroid antibodies in $36 \%$ compared to $9 \%$ in multiparous controls and $5 \%$ in nulliparous controls ${ }^{[8]}$. Matalon ST et al in 2001showed that elevated levels of thyroid auto antibodies are associated with increased rate of abortions in euthyroid women ${ }^{[9]}$. In the original Whickham study in the United Kingdom, performed in the 1970s, it was estimated that the prevalence of $\mathrm{Tg}-\mathrm{Ab}$ was $2 \%$ in the sample of 2799 people, while TPO-Abs were present in $6.8 \%$ of the sample ${ }^{[10]}$. The frequency increased with age among the pregnant women. The National Health and Nutrition Examination Survey (NHANES) data from the USA reviewed in 2002 showed TPO-Ab in $13 \%$ of the pregnant women had increased titres of anti TPO antibody. Similar to the findings in the Whickham study follow up, there was an increase in thyroid autoantibodies with age in pregnancy. NHANES also showed that the prevalence of TPO-Ab and $\mathrm{Tg}-\mathrm{Ab}$ was higher in Caucasians, as compared to African Americans ${ }^{[11]}$.

Prevalence of thyroid autoimmunity as measured by increased titre of anti TPO antibody in our study population was $18.30 \%$. (Fig:1) In the study done by Ahmed S. El-Halwagy, on a population in Egypt in 2017 the prevalence was $20 \%$ which is similar to our study. ${ }^{[12]}$

Thyroid hormonal status of the babies (measured from cord blood) according to the anti TPO antibody level has been given in the table no: 1 . The TSH and fT4 levels of the babies of the mothers of anti TPO antibody $\geq 40 \mathrm{U} / \mathrm{L}$ were $12.95 \pm 7.93$ (mean \pm SD) and $1.16 \pm 0.38$ (mean \pm $\mathrm{SD})$. For the babies of the mothers having anti TPO antibody $<40 \mathrm{U} / \mathrm{L}$, the TSH and fT4 levels were 9.96 \pm 6.83 (mean \pm SD) and $1.18 \pm 0.41$ (mean \pm SD).

In the study done by M. Polak et al, it is seen that there is increased incidence of congenital hypothyroidism in the babies of the mother having increased anti TPO antibody titres ${ }^{[13]}$.

Fetomaternal outcome according to the status of thyroid autoimmunity have been shown in table no 2. The outcome were compared among the cases with higher anti TPO antibody titres ( $\geq 40 \mathrm{U} / \mathrm{l})$ and those with the lower $(<40 \mathrm{U} / \mathrm{l})$. The comparison shows that, the patients with increased anti TPO antibody levels were having more incidence of all complications as measured for maternal outcome (APH, PPH \& maternal anaemia) \& fetal outcome (low APGAR score and low birth weight). The incidence of adverse maternal outcome was found to be statistically significant in thyroid autoimmunity (Anti TPO Antibody positive) for maternal anaemia $(\mathrm{Hb} \%$ $<10 \mathrm{mg} / \mathrm{dl}$ ) [odds ratio 2.32, $\mathrm{p}$ value $=0.0096$ ]

The incidence of adverse fetal outcome was found to be statistically significant in thyroid autoimmunity for the following parameters:

1. Low birth weight $(<2.5 \mathrm{~kg})$ [odd ratio 2.37, $\mathrm{p}$ value $=0.026]$

2. Low APGAR score [odd ratio 14.25, p value $<0.0001]$

There are numerous other studies which have shown similar facts. In the study done by Negro et al revealed that euthyroid TPO antibody positive pregnant women had an increased risk of preterm delivery ${ }^{[14]}$. In the study done by Karakosta in 2012 there was significantly increased number of low birth weight babies in patients with thyroid autoimmunity $^{[15]}$.

Pregnancy represents a challenge not only for thyroid function, but also for the immune system. It is important to consider the high prevalence of thyroid autoimmune disease in the reproductive period, which is significantly influenced by the modification of immune response in pregnancy.

Although immune tolerance in pregnancy frequently leads to amelioration of thyroid autoimmunity, the recognition and treatment of thyroid dysfunction is of crucial importance to avoid detrimental complications in mother and baby. On the other hand, the exacerbation of thyroid autoimmunity is expected after delivery, 
when the immune responsiveness increases, and therefore screening for thyroid dysfunction in women during pregnancy is of utmost importance.

\section{Conclusion}

The prevalence of increased titre of thyroid autoimmunity is $18.30 \%$, considering the normal level of anti TPO Antibody. The incidence of adverse maternal outcome was found to be statistically significant in the women positive for thyroid autoimmunity so far anaemia is concerned. The incidences of adverse fetal outcome in terms of low birth weight and low APGAR score were also found to be statistically significant in subjects with thyroid autoimmunity. Other maternal complications like antepartum and postpartum haemorrhages are also found to be more prevalent in thyroid autoantibody positive women but the finding was not significant statistically.

\section{Acknowledgement}

The authors acknowledge Prof. Saibal Kumar Mukherjee Principal and Prof. Sourav $\mathrm{Kr}$ Chattopadhyay, Medical Superintendent and Vice Principal, of NRS medical College for their necessary help and support.

\section{Sources of support: Nil}

\section{References}

1. Vanderpump MPJ. The epidemiology of thyroid disease. Br Med Bull 2011; 99:3951.

2. Greenman GW, Gabrielson MO, HowardFlanders J, Wessel MA, Thyroid dysfunction in pregnancy. Fetal loss and follow- up evaluation of surviving infants. N Eng J of Med 1962; 267: 426-31.

3. Gayathri R, Lavanya S, Raghavan K. Subclinical hypothyroidism and autoimmune thyroiditis in pregnancy: A study in South Indian subjects. J Assoc Physicians India. 2009;57:691-3.

4. Donny L. Chang, Elizabeth N. Pearce. Screening for maternal Thyroid dysfunction in pregnancy: A review of the clinical evidence and current guidelines. $\mathbf{J}$ Thyroid Res. 2013;2013:851326.

5. Karakosta P, Alegakis D, Georgiou V, Roumeliotaki T, Fthenou E, Vassilaki M, Boumpas D, Castanas E, Kogevinas M, Chatzi L. Thyroid dysfunction and autoantibodies in early pregnancy are associated with increased risk of gestational diabetes and adverse birth outcomes: J Clin Endocrinol Metabol. 2012; 97(12):4464-72.

6. Abbassi- Ganavati M, Greer FG. Pregnancy and laboratory studies: A reference table for clinicians. Obstet Gynecol. 2009; 114(6): 1326-31.

7. Stagnaro-Green A, Roman $\mathrm{SH}$, Cobin $\mathrm{RH}$, et al. Detection of at risk pregnancy by means of highly sensitive assays for thyroid auto antibodies. JAMA. 1990;264:1422-1425.

8. Bussen S, Steck T.Thyroid autoantibodies in euthyroid non-pregnant women with recurrent spontaneous abortions. Hum Reprod. 1995;10:2938-2940.

9. Matalon ST,Blank M ,Ornoy A,et al.The association between anti-thyroid antibodies and pregnancy loss. Am J Reprod Immunol.2001;45:72-77.

10. W. M. G. Tunbridge, D. C. Evered, R. Hall etal.The spectrum of thyroid disease in a community: the Whickham survey. Clinical Endocrinology.1977; 7:481-493.

11. J. G. Hollowell, N. W. Staehling, W. D. Flanders et al. Serum TSH, T4, and thyroid antibodies in theUnited States population (1988 to 1994): National Health and Nutrition Examination Survey (NHANES III).The Journal of Clinical Endocrinology \& Metabolism. 2002;87: 489-499.

12. Ahmed S. El-Halwagy. Study of the Relationship between Anti-Peroxidase Antibody and Miscarriage. Preterm Labor and IUGR in Egyptian Pregnant Women. 
Open Journal of Obstetrics and Gynecology.2017; 7:494-502.

13. M. Polak, I. Legac, E. Vuillard, J. Guibourdenche, M. Castanet, and D. Luton, Congenital hyperthyroidism: the fetus as a patient. Hormone Research. 2006;65: 235-242.

14. Negro, R., Formoso, G., Mangieri, T., Pezzarossa, A., Dazzi, D. and Hassan, H. Levothyroxine Treatment in Euthyroid Pregnant Women with Autoimmune Thyroid Disease: Effects on Obstetrical Complications. The Journal of Clinical Endocrinology \& Metabolism.2006; 91:2587-2591.

15. Karakosta, P., Alegakis, D., Georgiou, V., Roumeliotaki, T., Fthenou, E., Vassilaki, M., et al. (2012) Thyroid Dysfunction and Autoantibodies in Early Pregnancy Are Associated with Increased Risk of Gestational Diabetes and Adverse Birth Outcomes. The Journal of Clinical Endocrinology \& Metabolism.2012; 97:4464-4472. 